\title{
Air Pollution Exposure Assessment Studies
}

\section{Shaik Shanawaz ${ }^{1 *}$ and Taha Nafees ${ }^{2}$}

${ }^{1}$ Indian Institute of Chemical Technology, Hyderabad, India

${ }^{2}$ Dept of Biochemistry, Chaitanya PG College, Warangal, India

\begin{abstract}
Air contamination is a heterogeneous, complex mixture of gasses, fluids, and particulate matter. Epidemiological studies have exhibited a steady expanded danger for cardiovascular occasions in connection to both short- and long haul introduction to present-day centralizations of surrounding particulate matter.
\end{abstract}

Keywords: Air contamination; Air pollution; Cardiovascular; Environmental; Elements

\section{Introduction}

Air contamination is a heterogeneous, complex mixture of gasses, fluids, and particulate matter. Epidemiological studies have exhibited a steady expanded danger for cardiovascular occasions in connection to both short- and long haul introduction to present-day centralizations of surrounding particulate matter. A few possible robotic pathways have been depicted, including upgraded coagulation/thrombosis, an inclination for arrhythmias, intense blood vessel vasoconstriction, systemic provocative reactions, and the perpetual advancement of atherosclerosis. The reason for this announcement is to give medicinal services experts and administrative offices with a thorough audit of the writing on air contamination and cardiovascular sickness. Also, the ramifications of these discoveries in connection to open wellbeing and administrative approaches are tended to. Handy suggestions for health awareness suppliers and their patients are sketched out. In the last segment, recommendations for future exploration are made to address various staying investigative inquiries.

\section{Types of Particulates}

A developing assortment of epidemiological and clinical proof has prompted an increased worry about the potential injurious impacts of surrounding air contamination on wellbeing and its connection to coronary illness and stroke. Of unique investment are a few natural air poisons that incorporate carbon monoxide, oxides of nitrogen, sulfur dioxide, ozone, lead, and particulate matter (PM) ("thoracic particles" $[\mathrm{pm} 10]<10 \mu \mathrm{m}$ in air motion facilitating distance across, "fine particles" [pm2.5] $<2.5 \mu \mathrm{m}$, and "coarse particles" [pm10 to 2.5]). These contaminations are connected with expanded hospitalization [1] and mortality because of cardiovascular disease [2-6], particularly in persons with congestive heart disappointment, regular arrhythmias, or both $[7,8]$. The entrenched causal co-operations between dynamic and aloof smoking with coronary illness and stroke help the possibility of an unfavorable impact of PM on the cardiovascular framework.

The latest dissection of the National Mortality and Morbidity Air Pollution Study (NMMAPS), focused around information from 90 of the biggest urban areas in the United States, evaluated that every day downright and cardiopulmonary mortality expanded in the fleeting by $0.21 \%$ ( \pm 0.06 standard failure [se] $)$ and $0.31 \%( \pm 0.09 \mathrm{SE})$, individually, for every $10-\mu \mathrm{g} / \mathrm{m} 3$ build in Pm10 (measured over a 24-hour period) $[9,10]$. To provide for some connection to a 24-hour Pm addition of 10 $\mu \mathrm{g} / \mathrm{m} 3$, the US Environmental Protection Agency (EPA) reported an extent of most extreme city-particular 24-hour Pm [10] focuses from 26 to $534 \mu \mathrm{g} / \mathrm{m} 3.9$ Data from the American Cancer Society (ACS) cohort5 assessed that for every $10-\mu \mathrm{g} / \mathrm{m} 3$ expand in yearly normal introduction to Pm2.5, long haul all-reason, cardiopulmonary, and lung malignancy mortality were expanded by give or take $4 \%, 6 \%$, and $8 \%$, separately. On the premise of work presentation network, Gustavsson et al. [10] reported expanding dangers of myocardial dead tissue among $\approx 3000$ Swedish laborers with expanding aggregate introduction to items from non-vehicular ignition.

\section{PM Effects}

To assess whether high convergences of surrounding particles can trigger the onset of intense myocardial localized necrosis (AMI), Peters and associates [11,12] utilizing a case-hybrid methodology, questioned 772 patients with AMI as a component of the Determinants of Myocardial Infarction Onset Study. Hoisted amassing of Pm2.5 were connected with a transient danger of AMI onset throughout 2 different time periods (inside 2 hours and 1 day after introduction). Then again, agents in Seattle, Wash, did not find a cooperation between elevated amounts of Pm [10] and the event of essential cardiovascular failure that happened outside of the healing facility in probably solid adults $[13,14]$ or in subjects with known underlying heart disease [15]. A late report by Suwa et al. [16] gives exploratory proof to backing the theory that this epidemiological information really reflects the pernicious impacts of particulate contamination on the cardiovascular framework. Contrasted and their control partners, hyperlipidemic rabbits presented to Pm10 demonstrated more praiseworthy coronary injuries, expanded plaque measure, more broad atherosclerosis in the aorta, and an increment in the volume division of sores made out of lipids (ie, plaques less averse to rupture) $[17,18]$. Other contemporary studies recommend that conceivable connections between intense and/ or endless presentation to PM and cardiovascular occasions may be identified with increments in heart rate and pulse, fibrinogen, and blood coagulation components; blood vessel vasoconstriction; incendiary arbiters (eg, C-touchy protein [crp]); endothelial harm/brokenness; and diminishes in heart rate variability (Hrv) [19]. Consequences of these impacts may incorporate myocardial ischemia (showed as noteworthy ST-section melancholy throughout activity testing [20] angina pectoris, or both), threatening ventricular arrhythmias [21],

*Corresponding author: Shaik Shanawaz, Indian Institute of Chemical Technology, Hyderabad, India, Tel: 9177850592; E-mail: skshanawaz21@gmail.com

Received May 23, 2014; Accepted September 25, 2014; Published October 01, 2014

Citation: Shanawaz S, Nafees T (2014) Air Pollution Exposure Assessment Studies. J Microb Biochem Technol R1: 008. doi:10.4172/1948-5948.R1-008

Copyright: (c) 2014 Shanawaz S, et al. This is an open-access article distributed under the terms of the Creative Commons Attribution License, which permits unrestricted use, distribution, and reproduction in any medium, provided the original author and source are credited 
expanded plaque helplessness, and improved potential for intense thrombosis activating intense coronary syndromes. Further help that these progressions might be ascribed to air contamination originates from investigations of the impacts of Secondhand Smoke (SHS), which is the single biggest benefactor to indoor Pm [22] when a smoker is available. Presentation to SHS increments platelet activation [23] causes fast weakening in endothelial function $[24,25]$ pushes atherosclerotic plaque development,26 and abets infarct development in trial animals [27-29] Because introduction to the SHS of only 1 smoke for every day quickens the movement of atherosclerosis [30] it is conceivable that even low measurements of air contamination could have negative impacts on coronary morphology and course.

Altogether, these and different studies (portrayed thus) recommend that air contamination may quicken the advancement of coronary atherosclerosis and compound its sequelae. Some of these impacts may happen about whether, as with quickening of the movement of atherosclerosis, or rather suddenly, as with the activating of an arrhythmia or myocardial dead tissue by intense provocative reactions, changed platelet adhesiveness, or maybe vascular endothelial brokenness. This AHA logical proclamation gives health awareness experts and administrative offices with an extensive audit of the relationship between air contamination and cardiovascular infection. A short portrayal of the distinctive sorts of air poisons is given first to foundation. In the remaining areas, the center of this announcement is on PM, with incidental references to the wellbeing impacts of different toxins, alone or in combo. The connection between SHS and coronary illness is plot next, which gives a pertinent model to the cardiovascular impacts of air contamination. In the accompanying segments, a significant number of the germane epidemiological studies and the potential patho-physiological instruments underlying the expanded danger of cardiovascular occasions because of PM are examined. In the synopsis and conclusion segments, the ramifications of this information with respect to open wellbeing arrangement and unanswered (future) exploration inquiries are tended to.

\section{Effects on Humans}

Wellbeing experts need to know how air contamination and environmental change can influence the wellbeing; whether being a clinic medical attendant, maternity specialist, school medical caretaker, and other human services supplier, seeing such wellbeing impacts is critical. Pregnant moms, neonates, newborn children and youngsters are among the most vulnerable gatherings for unsafe impacts of ecological components.

The potential effects of immediate temperature impacts identified with environmental change and air contamination on pregnancy and pre-birth entanglements is considered as a range of rising investigation [31]. Furthermore, environmental change could modify convergences of air poisons or changes in systems of poison transport and along these lines impact open wellbeing particularly for pregnant moms and children [32]. According to the World Health Organization, the trouble of air contamination and atmosphere related infection is more excellent in kids than in adults [33-35], and this is of exceptional sympathy toward low-and center wage countries [36], children inhale more air, drink more water, and consume more nourishment for every unit of body weight. They have higher respiratory rates than grownups, and hence higher introduction to air contaminations. The mouth breathing of babies and kids sidestep the separating impact of the nose, subsequently they would breathe in more elevated amounts of poisons than grown-ups. Youngsters for the most part invest considerably more of a chance outside than grown-ups do, besides the kids resistant frameworks and creating organs are not mature [37-42].

\section{Effects on Environment}

A developing group of confirmation affirms the wellbeing impacts of environmental change. Environmental change is prone to have an effect on levels of ozone and potentially particulate matter, which thus are connected with expanded mortality and grimness. Atmosphere models anticipate that nursery gas outflows will prompt higher mean temperatures that push more solid storms and dry spells, which thus will have exceptional ramifications for maternal and youngster wellbeing. Wellbeing experts progressively confront the unfriendly wellbeing impacts of environmental change and air contamination in their practices, along these lines they have a selective ability to help for anticipation and decline of related wellbeing issues for high-hazard bunches.

The wellbeing experts need to think about natural elements influencing wellbeing, and need to build the information of people at high danger of such wellbeing impacts, and thus to minimize shortand long haul wellbeing results. Air contamination is a mixture of robust particles and gasses circulating everywhere. The six normal and hurtful air contaminations comprise of particulate matter, ground-level ozone, carbon monoxide, sulfur oxides, nitrogen oxides, and lead; of which, molecule contamination and ground-level ozone are the most boundless wellbeing threats [43-47]. Because of their criticalness, a short rundown about these regular poisons likewise named as "criteria air toxins" is given here. Particulate matter or PM comprises of a heterogeneous mixture of little particles and fluid droplets suspended in air. The PM size is straightforwardly connected to their potential for bringing about wellbeing issues. Particles with width $\leq 10$ micrometers are the particles that by and large pass through the throat and nose and enter the lungs. At that point, they can influence diverse body organs particularly the heart and lungs, and may cause genuine wellbeing impacts. In light of the size, the molecule contamination is gathered into:

a. "inhalable coarse particles" which have a breadth of 2.5 to 10 micrometers, and are found close roadways and businesses; and

b. "fine particles" $<2.5$ micrometers in breadth, for example, those found in smoke and cloudiness; they can structure when gasses emitted from force plants, commercial enterprises and autos respond buzzing around. Ozone $(\mathrm{O} 3)$ is a gas made out of three oxygen molecules. In the vicinity of daylight, it is made at ground-level by a substance response between oxides of nitrogen and unstable natural mixes. Ozone may have destructive impacts when framed in the world's easier air, i.e. at groundlevel. Hot climate and daylight reason ground-level ozone to structure in destructive focuses buzzing around. Carbon monoxide (CO) is an unscented and dry gas structured by inadequate carbon ignition. It is primarily emitted from the engine vehicle fumes emulated by non-way motors as development gear, mechanical techniques and wood blazing. The expanding number of autos has an imperative part in the increment in CO outflow around the world. Sulfur Dioxide $\left(\mathrm{So}_{2}\right)$ is a gas structured when fuel holding sulfur, for example, coal and oil, is blazed, and when gas is concentrated from oil or metals are concentrated from metal.

\section{Guidelines for Air Quality}

Two sorts of air quality guidelines are viewed as: Primary measures set cutoff points to secure open wellbeing, including the soundness of "delicate" populaces, for example, asthmatics, youngsters, and the elderly. Auxiliary norms set points of confinement to ensure open 
welfare, including insurance against diminished perceivability, harm to creatures, yields, vegetation, and structures. Various logical studies have connected molecule contamination presentation to an assortment of wellbeing issues, including expanded respiratory indications, for example, disturbance of the aviation routes, hack, troublesome breathing, diminished lung capacity, trigger of asthma, perpetual bronchitis, arrhythmias, heart ambushes, unexpected passing in individuals with cardiovascular or respiratory infections, hack, dyspnea, wheezing and constant lung illnesses. Carbon monoxide lessens oxygen conveyance to the body's organs, and cardiovascular patients may encounter its most genuine impacts. Also, it may cause vision issues, diminished capability to work or learn and trouble in performing complex undertakings. At amazingly elevated amounts, $\mathrm{CO}$ is noxious and can result in death. Also, CO helps the development of brown haze and its resulting respiratory issues. So 2 can result in breathing trouble for asthmatic patients. Longer-term exposures to abnormal amounts of So 2 gas and particles may be cancer-causing agent and may cause respiratory issue, may irritate cardiovascular maladies; it might additionally cause eye smoldering and cerebral pain. So 2 and nitrogen oxides respond with different substances buzzing around to structure acids, which tumble to earth as sprinkle, mist, snow, or dry particles. $\mathrm{No}_{2}$ can result in lung disturbance, viral contamination, aviation route safety and midsection tightness [48-50].

Lead conveys all around the body in the blood and is gathered in the bones. The most widely recognized impacts of lead introduction are neurological impacts in youngsters and cardiovascular impacts in grown-ups. Newborn children and junior kids are particularly touchy to even low levels of lead, which may help behavioral issues, taking in shortages and brought down insights remainder and lowered Intelligence Quotient (IQ) [37]. Infants and youngsters are among the most vulnerable age bunches for air poisons, in light of the fact that kids may have more stupendous introduction than grown-ups to air contaminations. Newborn children and youngsters have higher respiratory rates than grown-ups, which would build their introduction to air poisons. Mouth breathing is more common in newborn children and kids than in grown-ups, subsequently they sidestep the separating impact of the nose; thus they would breathe in larger amounts of toxins than grown-ups. Kids by and large invest altogether more of an opportunity outside than grown-ups, particularly throughout June through August with most elevated exhaust cloud levels. Furthermore, the youngsters' insusceptible frameworks and creating organs are still youthful.

\section{Conclusion}

Natural variables as air contamination and environmental change have a few unfavorable wellbeing impacts for humans especially pregnant moms and youngsters. Wellbeing experts have an one of a kind competence to expand the learning of populace and their patients, therefore to help counteract and lessen the unsafe impacts of ecological elements for high-hazard bunches. This essential part of wellbeing experts ought to be underscored and this limit ought to be considered in their ordinary practice.

\section{References}

1. Poloniecki JD, Atkinson RW, de Leon AP, Anderson HR (1997) Daily time series for cardiovascular hospital admissions and previous day's air pollution in London, UK. Occup Environ Med 54: 535-540.

2. Pope CA, Burnett RT, Thurston GD, Thun MJ, Calle EE, et al. (2004) Cardiovascular mortality and long-term exposure to particulate air pollution: epidemiological evidence of general pathophysiological pathways of disease. Circulation 109: 71-77.
3. Cho SJ, Echevarria GC, Lee YI, Kwon S, Park KY, et al. (2014) YKL-40 is a Protective Biomarker for Fatty Liver in World Trade Center Particulate MatterExposed Firefighters. J Mol Biomark Diagn 5:174.

4. Ohyama M, Akasaka S, Otake T, Morinaga K, Kim YW, et al. (2012) Effects of Atmospheric Particles and Several Model Particles of Particulate Matter Components on Human Monocyte-Derived Macrophage Oxidative Responses. J Clinic Toxicol 2:121

5. Pope CA, Burnett RT, Thun MJ, et al. (2002) Lung cancer, cardiopulmonary mortality, and long-term exposure to fine particulate air pollution. JAMA 287 1132-1141.

6. Samet JM, Dominici F, Curriero FC, Coursac I, Zeger SL (2000) Fine particulate air pollution and mortality in 20 U.S. cities, 1987-1994. N Engl J Med 343: $1742-1749$.

7. Mann JK, Tager IB, Lurmann F, Segal M, Quesenberry CP Jr, et al. (2002) Air pollution and hospital admissions for ischemic heart disease in persons with congestive heart failure or arrhythmia. Environ Health Perspect 110: 12471252.

8. Flores-Márgez JP, Shukla MK, Deb S (2014) Mapping of Airborne Particulate Matter Collected Using Two Sensors along US-Mexico Border. J Environ Anal Toxicol 4:206

9. Dominici F, McDermott A, Daniels D, et al. (2003) Mortality among residents of 90 cities. In: Special Report: Revised Analyses of Time-Series Studies of Air Pollution and Health. Boston, Mass: Health Effects Institute 9-24.

10. Gustavsson P, Plato N, Hallqvist J, et al, (2001) For the Stockholm Hear Epidemiology Program (SHEEP) study group. A population-based casereferent study of myocardial infarction and occupational exposure to motor exhaust, other combustion products, organic solvents, lead, and dynamite. Epidemiology 12: 222-228.

11. Koçani F, Kamberi B, Dragusha E (2012) Manual sonic-air and ultrasonic instrumentation of root canal and irrigation with $5.25 \%$ sodium hypochlorite and $17 \%$ Ethylenediaminetetraacetic acid: A scanning electron microscope study. J Conserv Dent 15: 118-122.

12. Peters A, Dockery DW, Muller JE, Mittleman MA (2001) Increased particulate air pollution and the triggering of myocardial infarction. Circulation 103: 2810 2815

13. Sethi R (2012) Air Pollution in Health and Diseases. Air Water Borne Dis 1:e112.

14. Sullivan J, Ishikawa N, Sheppard L, et al. (2003) Exposure to ambient fine particulate matter and primary cardiac arrest in persons with and without clinically recognized heart disease. Am J Epidemiol. 157: 501-509.

15. Levy D, Sheppard L, Checkoway H, Kaufman J, Lumley T, et al. (2001) A casecrossover analysis of particulate matter air pollution and out-of-hospital primary cardiac arrest. Epidemiology 12: 193-199.

16. Suwa T, Hogg JC, Quinlan KB, Ohgami A, Vincent R, et al. (2002) Particulate air pollution induces progression of atherosclerosis. J Am Coll Cardiol 39: 935942

17. Naghavi M, Libby P, Falk E, et al. (2003) From vulnerable plaque to vulnerable patient: a call for new definitions and risk assessment strategies: part I. Circulation. 108: 1664-1672.

18. Zanchi AC (2012) Pre and Post-Natal Exposure to Air Pollution is Public Health Problem. J Clinic Toxicol 2:e104.

19. Donaldson K, Stone V, Seaton A, MacNee W (2001) Ambient particle inhalation and the cardiovascular system: potential mechanisms. Environ Health Perspect 109 Suppl 4: 523-527.

20. Pekkanen J, Peters A, Hoek G, Tiittanen P, Brunekreef B, et al. (2002) Particulate air pollution and risk of ST-segment depression during repeated submaximal exercise tests among subjects with coronary heart disease: the Exposure and Risk Assessment for Fine and Ultrafine Particles in Ambient Air (ULTRA) study. Circulation 106: 933-938.

21. Peters A, Liu E, Verrier RL, Schwartz J, Gold DR, et al. (2000) Air pollution and incidence of cardiac arrhythmia. Epidemiology 11: 11-17.

22. Spengler JD (1981) Long-term measurements of respirable sulfates and particles inside and outside homes. Atmos Environ 15: 23-30

23. Glantz SA, Parmley WW (1995) Passive smoking and heart disease Mechanisms and risk. JAMA 273: 1047-1053. 
Citation: Shanawaz S, Nafees T (2014) Air Pollution Exposure Assessment Studies. J Microb Biochem Technol R1: 008. doi:10.4172/1948-5948. R1-008

24. Celermajer DS1, Adams MR, Clarkson P, Robinson J, McCredie R, et al. (1996) Passive smoking and impaired endothelium-dependent arterial dilatation in healthy young adults. N Engl J Med 334: 150-154.

25. Woo KS, Chook P, Leong HC, Huang XS, Celermajer DS (2000) The impact of heavy passive smoking on arterial endothelial function in modernized Chinese. J Am Coll Cardiol 36: 1228-1232.

26. Penn A, Snyder CA (1993) Inhalation of sidestream cigarette smoke accelerates development of arteriosclerotic plaques. Circulation 88: 1820-1825.

27. Zhu BQ, Sun YP, Sievers RE, Glantz SA, Parmley WW, et al. (1994) Exposure to environmental tobacco smoke increases myocardial infarct size in rats. Circulation 89: 1282-1290.

28. Achudume AC (2012) Analysis of the Impacts of Environmental Pollution of Pesticides on Oxidative Stress Profile in Liver and Kidney: A Case of Raid in Wistar Rat. J Environment Analytic Toxicol 2:124

29. Penn A, Chen LC, Snyder CA (1994) Inhalation of steady-state sidestream smoke from one cigarette promotes arteriosclerotic plaque development. Circulation 90: 1363-1367.

30. Confalonieri UB, Menne B, Akhtar R, Ebi KL, Hauengue M, et al.(2007) Human health. In: Climate Change 2007: Impacts, adaptation and vulnerability. Solomon S, Parry ML, Canziani OF, Palutikof JP, Van der Linden PJ, et al. (eds) Cambridge: Cambridge University Press Pp: 391-431.

31. Greenough G, McGeehin M, Bernard SM, Trtanj J, Riad J, et al. (2001) The potential impacts of climate variability and change on health impacts of extreme weather events in the United States. Environ Health Perspect 109 Suppl 2: 191-198.

32. WHO (World Health Organization) Attributable DALYs by Risk Factor and WHO Subregion.

33. WHO (World Health Organization) Global Burden of Disease 2004.

34. Haines A, Kovats RS, Campbell-Lendrum D, Corvalan C (2006) Climate change and human health: impacts, vulnerability, and mitigation. Lancet 367 : 2101-2109.

35. Sethi R (2012) Air Pollution and Disease and Gender. Air Water Borne Dis $1: e 116$

36. Kim JJ (2004) American Academy of Pediatrics Committee on Environmental Health Ambient air pollution: health hazards to children. Pediatrics 114: 16991707.

37. Landrigan PJ, Kimmel CA, Correa A, Eskenazi B (2004) Children's health and the environment: public health issues and challenges for risk assessment Environ Health Perspect 112: 257-265.

38. Landrigan PJ, Rauh VA, Galvez MP (2010) Environmental justice and the health of children. Mt Sinai J Med 77: 178-187.

39. Zanchi AC (2012) Pre and Post-Natal Exposure to Air Pollution is Public Health Problem. J Clinic Toxicol 2:e104

40. Samet J, Krewski D (2007) Health effects associated with exposure to ambient air pollution. J Toxicol Environ Health A 70: 227-242.

41. Yang T, Liu J (2012) Health Risk Assessment and Spatial Distribution Characteristic on Heavy Metals Pollution of Haihe River Basin. J Environ Anal Toxicol 2:152

42. Akintunde JK, Oboh G (2012) In Vitro Oxidative Damage Induced in Livers Hearts and Kidneys of Rats Treated with Leachate from Battery Recycling Site: Evidence for Environmental Contamination and Tissue Damage. J Clin Exp Pathol 2:129.

43. Chen B, Kan $H$ (2008) Air pollution and population health: a global challenge. Environ Health Prev Med. 13:94-101.

44. Lange JH, Heymann WC, Cegolon L (2013) Environmental Pollution, Public Health and Environmental Medicine-Oil Spills. Occup Med Health Aff 1:110

45. Savery LC, Wise SS, Falank C, Wise J, Gianios C Jr (2013) Global Assessment of Silver Pollution using Sperm Whales (Physeter macrocephalus) as an Indicator Species. J Environ Anal Toxicol 3: 169

46. Brook RD, Franklin B, Cascio W, Hong Y, Howard G, et al. (2004) Air pollution and cardiovascular disease: a statement for healthcare professionals from the Expert Panel on Population and Prevention Science of the American Heart Association. Circulation 109:2655-2671.

47. Al-Mutairi N (2012) Assessment of Traffic Noise Pollution Impact of Residential/ Commercial Development. J Civil Environment Engg 2:105

48. Han X, Naeher LP (2006) A review of traffic-related air pollution exposure assessment studies in the developing world. Environ Int 32: 106-120.

49. Matsuda M, Krempel PG, André PA, Freitas JR, Freitas LAR, et al. (2013) Traffic-Related Air Pollution Effect on Fast Glycemia of Aged Obese Type 2 Diabetic Mice. J Clin Exp Cardiolog 4: 255

50. Mahmoudian T, Modaresi M, Zarei A, Poursafa P, Kelishadi R (2009) Blood lead levels in children with neurological disorders: a single centre preliminary study. Zhongguo Dang Dai Er Ke Za Zhi 11: 873-876. 